\title{
MONITORING OF IN-FIELD VARIABILITY FOR SITE SPECIFIC CROP MANAGEMENT THROUGH OPEN GEOSPATIAL INFORMATION
}

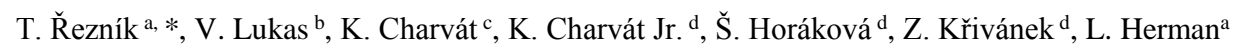 \\ ${ }^{a}$ Masaryk University, Faculty of Science, Department of Geography, Kotlářská 2, 61137 Brno, Czech Republic - \\ tomas.reznik@sci.muni.cz \\ ${ }^{\mathrm{b}}$ Mendel University, Faculty of Agronomy, Department of Agrosystems and Bioclimatology, Brno, Czech Republic - \\ vojtech.lukas@mendelu.cz \\ ${ }^{c}$ Baltic Open Solutions Center, Krišjāña Barona iela 32-7, Rīga, Latvia - bosc@bosc.lv \\ d Wirelessinfo, Cholinská 19, Litovel, Czech Republic - (charvat_junior, horakova, krivanek)@ wirelessinfo.cz
}

ThS2: Operational Remote Sensing Application Services

KEYWORDS: satellite images, location-based services, environmental monitoring, open data, cloud computing,

\begin{abstract}
:
The agricultural sector is in a unique position due to its strategic importance around the world. It is crucial for both citizens (consumers) and the economy (both regional and global), which, ideally, should ensure that the whole sector is a network of interacting organisations. It is important to develop new tools, management methods, and applications to improve the management and logistic operations of agricultural producers (farms) and agricultural service providers. From a geospatial perspective, this involves identifying cost optimization pathways, reducing transport, reducing environmental loads, and improving the energy balance, while maintaining production levels, etc.

This paper describes the benefits of, and open issues arising from, the development of the Open Farm Management Information System. Emphasis is placed on descriptions of available remote sensing and other geospatial data, and their harmonization, processing, and presentation to users. At the same time, the FOODIE platform also offers a novel approach of yield potential estimations. Validation for one farm demonstrated $70 \%$ successful rate when comparing yield results at a farm counting 1'284 hectares on one hand and results of a theoretical model of yield potential on the other hand. The presented Open Farm Management Information System has already been successfully registered under Phase 8 of the Global Earth Observation System of Systems (GEOSS) Architecture Implementation Pilot in order to support the wide variety of demands that are primarily aimed at agriculture and water pollution monitoring by means of remote sensing.
\end{abstract}

\section{INTRODUCTION}

The agriculture sector is in a unique position due to its strategic importance around the world. It is crucial for both the citizens (consumers) and the economy (regional and global) which, ideally, should make the whole sector a network of interacting organisations. Rural areas are of particular importance with respect to the agri-food sector, and should be specifically addressed within this scope. The different groups of stakeholders involved in agricultural activities have to manage many different and heterogeneous sources of information that need to be combined in order to make economically and environmentally sound decisions, which include (among others) the definition of policies (subsidies, standardisation and regulation, national strategies for rural development, climate change), development of sustainable agriculture, crop recollection timing and pricing, plagues detection, etc.

From a global perspective, agriculture is the single largest user of freshwater resources, each country using an average of $70 \%$ of all its surface water supplies. An essential proportion of agricultural water is recycled back to surface water and/or groundwater. Agriculture, and especially water, pollution is therefore the subject of (inter)national legislation, such as the Clean Water Act in the United States of America (United States Environmental Protection Agency, 1972), the European Water
Framework Directive (European Commission, 1991), and the Law of the People's Republic of China on the Prevention and Control of Water Pollution (Ministry of Water Resources of the People's Republic of China, 1984).

In this context, future agriculture knowledge management systems have to support not only direct profitability of agriculture and environment protection, but also the activities of individuals and groups allowing efficient collaboration among groups in agri-food industry, consumers, public administration and wider stakeholders communities, especially in the rural domain.

In the agriculture domain, of the period of past 20 years may be characterized as a shift from (conventional) farming to precision farming. As stated by Auernhammer (2001), "precision farming makes use of information technologies in agriculture. With the satellite positioning system and electronic communication standards, position and time may be integrated into all procedures connected to farming". Nemenyi et al. (2003) emphasis the necessity of a Geographic Information System (GIS) as a computing background to generate a complex view of fields and to make valid agrotechnological decisions.

The European project called "Farm-Oriented Open Data in Europe" (FOODIE), funded between the years 2014 and 2017, addresses the above-mentioned issues. The FOODIE project aims at building an open and interoperable agricultural

\footnotetext{
* Corresponding author
} 
specialized platform hub on the cloud for the management of spatial and non-spatial data relevant for farming production; for discovery of spatial and non-spatial agriculture related data from heterogeneous sources; integration of existing and valuable European open datasets related to agriculture; data publication and data linking of external agriculture data sources contributed by different public and private stakeholders allowing to provide specific and high-value applications and services for the support in the planning and decision-making processes of different stakeholder groups related to the agricultural and environmental domains.

\section{GEOSPATIAL DATA IN PRECION FARMING}

When talking about GIS, we also have to bear in mind geospatial data that are crucial for any GIS functionality. Four key areas of geospatial data may be defined as a pre-requisite for any precision farming application:

- Operative aerial remote sensing for the whole area of interest when mapping the fields at high spatial resolution but with low frequency (also known as temporal resolution). The aim is to prepare the prescription maps for spatially variable applications of fertilizers and pesticides, estimated by the spectral measurement of crop parameters. The frequency of the survey depends on the crop type, agronomical operations, crop management intensity and weather conditions. Aerial imaging is usually carried out using multispectral camera by an external provider of photogrammetric services. Analyses may be performed through interpretation algorithms after a pre-processing of the acquired images, i.e. radiometric and geometric corrections.

- Periodic satellite remote sensing for wide-ranging identification of spatial variability and simultaneously capturing the dynamics of vegetation growth, both at medium level of spatial resolution; such as in the case of Landsat 8 images 30 metres per pixel, once per 14 days. European Sentinel-2 data seem to provide a valuable source for periodic satellite remote sensing, which is going to significantly shorten the temporal resolution, e.g. to about 6 days for the most of the Central Europe when combining Landsat and Sentinel data. The main information lies in the vegetation indices determined from R (red) and NIR (near infrared) bands (see also Figure 1 and section 4.1 for further details). The absolute values of vegetation indices, their relative to mean value of the field and change detection are used for assessment of crop stands and delineating management zones.

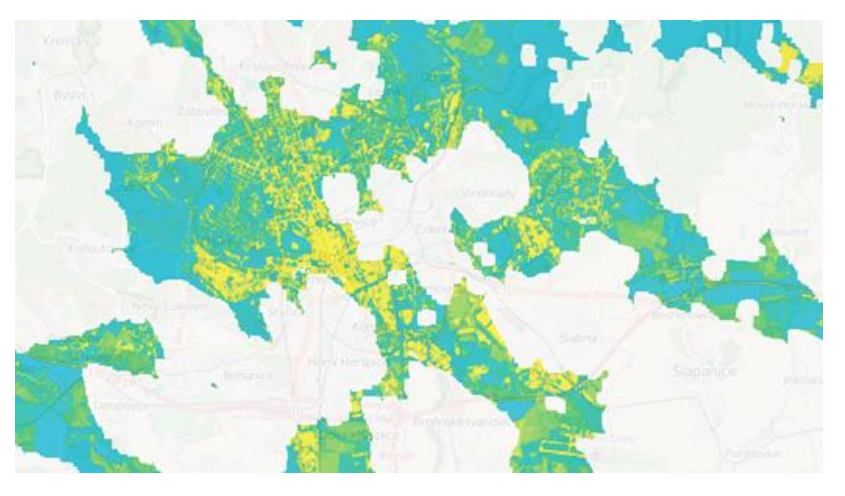

Figure 1. Vegetation index computed from Landsat 8 satellite images used to capture the dynamics of vegetation growth.

Yellow colour means vegetation under stress (in this figure rural areas within Brno city) while blue colour means growing vegetation with the highest possible density of green leaves.

- Machinery monitoring typically obtained through the Global Navigation System of Systems (GNSS), no matter whether it is the American Global Positioning System (GPS), European Galileo, Russian Glonass, Chinese BeiDou or any other. The basic principles are the same for any of the above mentioned even though technical details may vary. A GNSS receiver is mounted on a moving vehicle, typically a tractor and/or an application machine. We may then track both the position and trajectory of a tractor/application machine as depicted in Figure 2. Experiments were made also with cell-phone based monitoring as described by Reznik et al. (2015).

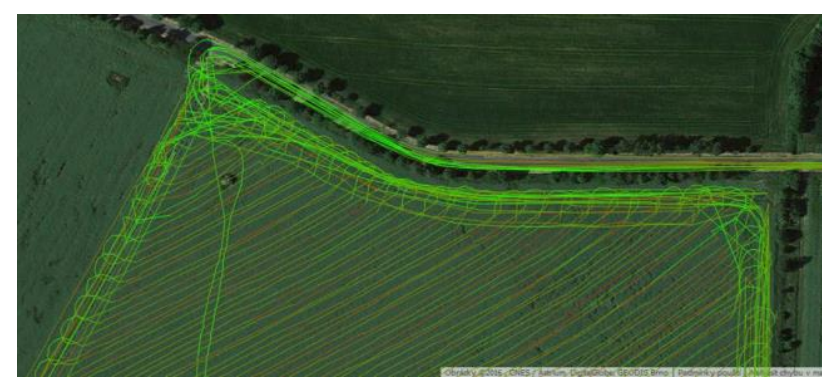

Figure 2. Trajectory of a tractor at the Tršická zemědělská farm (the Czech Republic) during one day as recorded by a GNSS receiver. Various colours of trajectory were used to distinguish the amount of fuel used per hour (green means consumption up to 25 litres per hour while red means consumption between 26 and 56 litres per hour).

- Meteorological monitoring at a farm level to capture detailed dynamics of weather conditions on the ground. Weather data together with its position are recorded at the specific localities in high frequency (between 10 and 15 minutes). The main goal is to obtain data for modelling of crop growth and to support decision making by agronomists for plant protection (prediction of the plant pests and infestation), plant nutrition (crop growth and nutrient supply), soil tillage (soil moisture regime) and irrigation (soil moisture).

All kinds of the above mentioned data are used within a Farm Management Information System (FMIS) which is nothing else than GIS with agro-specific decision-making processes support. Decision making processes within any FMIS aim at two levels:

- Economic, which are the primary concern of a farmer: These are related to reductions of fuel, time of the employees, the amount of fertilizers and/or pesticides etc.;

- Ecological, which are the primary concern of environmental organisations, public administration and citizens; and which also partly overlap with economic motivations such as minimizing the environmental burden through lowering the amount of nitrogen applied through fertilizer into the ground. 
To sum up, geospatial data are the basis for any FMIS; no matter whether they follow economic or ecological motivations. Principles of geospatial data harmonization in such cases are described by Cerba et al. (2012), Feiden et al. (2011), Kubicek et al. (2013) and Stampach et al. (2015).

\section{OPEN FARM MANAGEMENT INFORMATION SYSTEM}

Precision farming relies on geospatial data and functionality that are available through an FMIS. Any FMIS may also be considered a kind of Geographic Information System (GIS) as it provides answers to two basic questions: what has happened and where. FMIS effectiveness from the geospatial point of view is limited chiefly by the lack of accurate data.

It is a paradox situation since there are proprietary FMIS's on one hand and there is request for open data and services to power proprietary FMIS's on the other hand. A way out may be found in a form of an Open Farm Management Information System (OpenFMIS). We would like to emphasize that an OpenFMIS also uses both open and proprietary data. Open data are used as inputs into an OpenFMIS, where geospatial data are the best example; e.g. starting from satellite and aerial images through cadastre to zones where the usage of nitrogen is forbidden. Proprietary data typically comprise sensitive economic information like turnover of a farm, consumption of fertilizers/pesticides/fuels, wages of employees etc. Proprietary data remain in the system, no matter whether it is a FMIS or an OpenFMIS. The greatest difference between FMIS and OpenFMIS lies in the presence of open application programming interfaces that allow (mostly) consuming data and/or functionality offered by other open applications. An OpenFMIS is also capable of exporting non-protected data, such as better geometrical representation of a field. An OpenFMIS also offers modularity, i.e. any component respecting geospatial/information technology standards may be added or taken away.

Moreover, world-wide concepts like the Digital Earth and Global Earth Observation System of Systems (GEOSS) are the ideal candidates for the integration of such agricultural pollution data around the world.

\subsection{FOODIE as OpenFMIS}

FOODIE approach supports better adoption of Information and Communication Technologies (ICT) and also enables better collaboration of different stakeholder across the agri-food chain. It supports trusted model of Software as Services for farming sector. This will help farmers employ a new type of solution without necessary investment and also easy integration of existing platform trough interoperable interfaces. This also incorporates the support of mobility platform - accessing information and knowledge everywhere and also the integration of different devices into all systems - as well as guarantees accessibility of different types of information.

FOODIE platform could be the "glue" in-between the public and private sectors by acting as a central platform (e.g., Land Parcel Identification System ICT system combined with intelligent and underlying hardware and software infrastructure that allows storing farmer's data (unique land parcel ids inside a region, farming activities performed), land owners, land use, orthoimages, satellite data etc. An open data model for (precision) agriculture was defined as a backbone of the FOODIE platform, as described by Reznik et al. (2015). Part of these datasets would remain private (e.g., famer data) whereas others like the orthoimages and satellite data plus derived data from all European Member States and other open datasets could be accessed and used by all other user groups beside the Ministry of a Member State. The EU Directive concerning the re-use of public sector information sets down the legal framework in this respect. This would definitely change the ICT use in agriculture and forestry. As seen in the previous section, the INSPIRE Directive also guides into the same direction, that is, to establish an infrastructure for spatial information in Europe for the purpose of EC environmental policies or activities which might have an impact on the environment (see also Skokanova, 2013).

In order to implement the FOODIE concept and the associated service platform hub, the project aims at accomplishing the following technological objectives:

- to make use of the existing spatial information resources and services for various domains coming from different initiatives like INSPIRE (INfrastructure for SPatial InfoRmation in Europe; see Reznik, 2013), Copernicus, GNSS, Galileo, GEOSS (Global Earth Observation System of Systems; see Diaz, Schade, 2011, GBIF (Global Biodiversity Information Facility), EUNIS (European Nature Information System) etc., where the European Commission and the Member States have invested heavily over the past decade;

- to design and provide an open and interoperable geospatial platform hub on the cloud based on the existing software components from research results and available solutions in the market (mostly opensource) that includes:

- the integration of external agriculture production and food market data using the principles of Open Linked Data

- an open and flexible lightweight Application Programming Interface (API), that allows private and public stakeholders in the agricultural and environmental area to publish their own datasets (e.g., datasets provided by local sensor networks deployed in situ in farms, knowledge from farm communities, agricultural services companies, etc.) and make it available via the platform hub as open linked data (and enabling it to further processing and reasoning over it)

- $\quad$ specific and high-value applications and services for the support in the planning and decision-making processes of the different stakeholders groups

- provision of security mechanisms to prevent the unauthorised access and use of the platform users' personal information as well as the data published by them

- a marketplace where data can be discovered and exchanged but external companies can also publish their own agricultural applications based on the data, services and applications provided by FOODIE.

The following section narrows the focus on the issues related to open-accessible monitoring of geospatial in-field variability since other issues are out of the scope of this paper. 


\section{MONITORING OF IN-FIELD VARIABILITY}

\subsection{Vegetation, water and moisture indices}

Based on information provided in the section 2, derived data from satellite images are used in the domain of (precision) agriculture to achieve maximum crop yield at minimum costs. Remote sensing techniques are also used for early detections of (potential) threats in a field, including their position and spatial variations as depicted in Figure 3. Visible (red, green and blue bands) and near-infrared portion of the electromagnetic spectrum are the most commonly used features for the monitoring of crops (growth/health/stress/...), nitrogen stress etc.

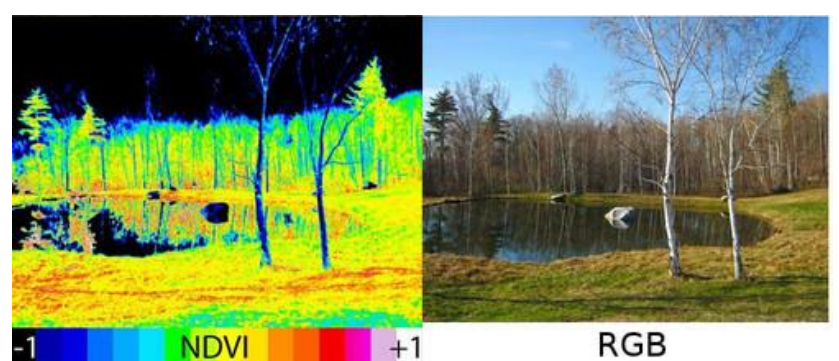

Figure 3. The same area captured by colour photo in visible portion of the spectrum (right) and Normalized Difference Vegetation Index (left) allowing to discover information not directly available within the visible portion of the spectrum (figure adopted from Warren, 2015).

Plants absorb or reflect rays in various wavelengths in a unique manner according to their cell structures, leaf and surface widths, amount of water in their bodies and their positions in their natural environments. Each plant species has a unique cell structure and position in nature. Thus, it is possible to distinguish plant species from each other.

Generally, plants absorb light in the wavelength between 0.4 and $0.7 \mu \mathrm{m}$, which is called the visible light region. While they absorb a very little portion of the infrared rays, they reflect a very large portion of them.

Computed indices can be defined as follows. Vegetation index provides a measurement of the presence of green vegetation on the land surface. Water indices are used to detect and monitor liquid water condition of vegetation canopies over large areas; and finally moisture indices are used to evaluate the soil moisture values. The FOODIE platform offers to registered users three kinds of vegetation/water/moisture indices which are conceptually defined in Henrich et al. (2011).

Landsat 8, Sentinel-2 and MODIS data are used as the inputs for the following indices:

- vegetation as a set of four options, namely:

- Normalized Difference 750/710 Red Edge $N D V I$ defined as a ratio of the following wavelengths in nanometres: [770:780] + [784:790] / [655:665] + [676:685];

- Enhanced Vegetation Index defined as: 2.5 NIR - RED ( NIR + 6 RED -

7.5 BLUE ) +1 ;

- CASI NDVI defined as a ratio of the following wavelengths in nanometres: ( $[770: 780]+[784: 790])-([655: 665]+$ $[676: 685])([770: 780]+[784: 790])+($ $[655: 665]+[676: 685])$

- water as a set of three options, namely:
- CASI TM4/3 defined as a ratio of the following wavelengths in nanometres: $[770: 780]+[784: 790][655: 665]+$ [676:685];

- Normalized Difference 750/650 defined as a ratio of the following wavelengths in nanometres: $(750 \mathrm{~nm}-650 \mathrm{~nm}) /(750 \mathrm{~nm}+$ 650nm);

- Normalized Difference 750/705 Chl NDI defined as a ratio of the following wavelengths in nanometres: $750 \mathrm{~nm}-705 \mathrm{~nm}$ $750 \mathrm{~nm}+705 \mathrm{~nm}$;

- moisture as a set of three options, namely:

- Simple Ratio 1599/819 Moisture Stress Index 2 defined as a ratio of the following wavelengths in nanometres: $1599 \mathrm{~nm} /$ 819nm;

- Simple Ratio 1600/820 Moisture Stress Index defined as a ratio of the following wavelengths in nanometres: $1600 \mathrm{~nm}$ $820 \mathrm{~nm}$;

- Global Vegetation Moisture Index defined as: $(\mathrm{NIR}+0.1)-(\mathrm{SWIR}+0.02) /(\mathrm{NIR}+$ $0.1)+($ SWIR + 0.02)

Vegetation, Water and Moisture Indexes are important measurements which provide geospatial information about farm fields and crops. These indices require advanced geoprocessing capabilities and are implemented by means of the OGC Web Processing Service (WPS) (Schutt, 2007) through a NetCad Suite, a component of the FOODIE platform. The indices are calculated by obtaining a single value indicating the density of vegetation by applying mathematical operations to reflection values with different wavelengths in electromagnetic spectrum.

\subsection{Yield potential}

Yield potential zones are areas with the same yield level within the fields. Yield is the integrator of landscape and climatic variability and as such, it provides useful information for identifying management zones as defined by Evans, Fischer (1999) and Kleinjan et al. (2007). This represents a basic delineation of management zones for site specific crop management, which is usually based on yield maps over the past few years. The presence of complete series of yield maps for all fields is rare, thus remote sensed data are analysed to determine the field variability of crops through vegetation indices.

The yield potential concept of the FOODIE platform aims at establishing a general model for yield potential zones for almost any kind of crop. However, such universality comes at a price. The model is capable of expressing significant spatial variations of a crop yield on a plot by distinguishing three kinds of values: below average, average and excessing average. On the other hand, the model depicts spatial variations within a plot, and therefore it may be misleading when trying to compare the yield zones between the plots. Altogether, we may conclude that some area(s) in a plot has significantly lower productivity then another and take such information into the decision making process. On the contrary, we cannot define that it is better to produce a crop on plot A or plot B.

So far, ESPA (United States Geological Survey's Earth Resources Observation and Science Center Science Processing Architecture repository) of LANDSAT satellite images is being used as the main data source, which offers surface reflectance products, main vegetation indices (NDVI, EVI) and clouds identification by CFmask algorithm. A selection of scenes from 
the past eight years was made for a farm area to collect cloudfree data related to the second half of vegetation period. Yield potential is calculated for separate scenes as the relation of each pixel to mean value of the whole field. In the last step, all scenes are combined and median value of yield potential is calculated. After full operation of Sentinel 2A/B satellites, calculation of yield potential will be enhanced by these vegetation products.

A concept of the yield potential was successfully validated. It was proven that the whole evaluated farm, Tršická zemědělská in the Czech Republic, has the spatial variation of a yield potential equal to $70 \%$ when comparing yield results with estimations of the yield potential. The evaluated farm lies in the Czech Republic and its acreage is about 1'284 hectares. Ongoing research follows two main directions. The first one is aiming at optimising the algorithm to increase the probability of the yield prediction up to $90 \%$. Another direction of the current research focuses on implementation of the yield potential as an open Web service, namely as an OGC Web Processing Service (Schutt, 2007).

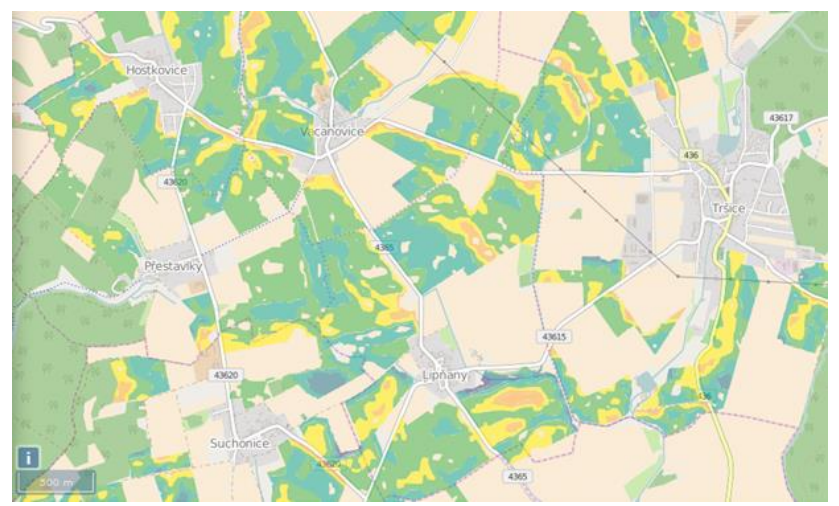

Figure 4. Demonstration of the yield potential zones in the Tršická zemědělská farm (the Czech Republic). Orange and yellow areas depicts zones with high yield potential, medium green with average and dark green zones with low yield potential.

\section{CONCLUSIONS}

The FOODIE platform represents a set of open geospatial tools aiming to provide support to stakeholders within and beyond the domain of (precision) agriculture. As such, data and techniques of remote sensing were also integrated into the platform.

Three kinds of each of vegetation, water and moisture indices are available to registered users as an OGC Web Processing Service. The algorithms used within such services are widely known and well-documented for their agricultural applications. At the same time, the FOODIE platform also offers a novel approach of yield potential estimations. Validation for one farm demonstrated $70 \%$ successful rate when comparing yield results at a farm counting 1'284 hectares on one hand and results of a theoretical model of yield potential on the other hand. The ongoing research aims at increasing the successf rate through a more complex algorithm.

The presented FOODIE platform has been registered under the GEOSS (Global Earth Observation System of Systems) Architecture Implementation Pilot - Phase 8 in order to support the wide variety of demands that are primary aimed at agriculture and water pollution monitoring.

\section{ACKNOWLEDGEMENTS}

This project has received funding from the European Union's Seventh Framework Programme for research, technological development and demonstration under grant agreement No. 621074 named "Farm-Oriented Open Data in Europe" (FOODIE), from the Horizon 2020 research and innovation programme under grant agreement No. 633945 designated "Farming Tools for external nutrient Inputs and water Management" (FATIMa) and from the Grant No. MUNI/A/1315/2015, the "Integrated Research of Environmental Changes in Landscape", awarded by Masaryk University, the Czech Republic.

\section{REFERENCES}

Auernhammer, H., 2001. Precision farming - the environmental challenge. Computers and Electronics in Agriculture, 30 (1-3), pp. 31-43.

Cerba, O., Charvat, K., Janecka, J., Jedlicka, K., Jezek, J., Mildorf, T., 2012. The Overview of Spatial Data Harmonisation Approaches and Tools. In: Proceedings of the 4th International Conference on Cartography and GIS, Albena, Bulgaria, Vol. 1, pp. 113-124.

Diaz, L., Schade, S. 2011. GEOSS Service Factory: Assisted Publication of Geospatial Content. In: Lecture Notes in Geoinformation and Cartography - Advancing Geoinformation Science for a Changing World, Utrecht, Netherlands, pp. 423442.

European Commission, 1991. "Council Directive 91/676/EEC of 12 December 1991 concerning the protection of waters against pollution caused by nitrates from agricultural sources", Brussels, Belgium http://eur-lex.europa.eu/legalcontent/EN/TXT/HTML/?uri=CELEX:31991L0676\&from=EN (31 Dec 1991).

Evans, L. T., Fischer, R. A. 1999. Yield Potential: Its Definition, Measurement, and Significance. Crop Science 39 (6), pp. 1544-1551.

Feiden, K., Kruse, F., Reznik, T., Kubicek, P., Schentz, H., Eberhardt, E., Baritz, R., 2011. Best Practice Network GS SOIL Promoting Access to European, Interoperable and INSPIRE Compliant Soil Information. In: ISESS 2011, 359, Heidelberg, Germany, pp. 226-234.

Henrich, V., Krauss, G., Götze, C., Sandow, C. 2011. "Index DataBase, A database for remote sensing images", Bonn, Germany http://www.indexdatabase.de/ (2011).

Kleinjan, J., Clyde, D. E., Carlson, C. G., Clay, S. A., 2007. Productivity zones from multiple years of yield monitor data. In: GIS applications in agriculture. Boca Raton, United States of America, pp. 65-70.

Kubicek, P., Kozel, J., Stampach, R., Lukas, V., 2013. Prototyping the visualization of geographic and sensor data for agriculture. Computers and Electronics in Agriculture, 97(9), pp. 83-91. 
Ministry of Water Resources of the People's Republic of China, 1984. "Law of the People's Republic of China on the Prevention and Control of Water Pollution", Beijing, China http://www.mwr.gov.cn/english/laws.html (2015).

Nemenyi, M., Mesterhazi, P. A., Pecze, Z., Stepan, Z., 2003. The role of GIS and GPS in precision farming. Computers and Electronics in Agriculture, 40 (1-3), pp. 45-55.

Reznik, T., 2013. Geographic information in the age of the INSPIRE Directive: discovery, download and use for geographical information research. Geografie, 118 (1), pp. 7793.

Reznik, T., Charvat, K. jr., Charvat K., Horakova, S., Lukas, V., Kepka, M., 2015. Open Data Model for (Precision) Agriculture Applications and Agricultural Pollution Monitoring. In: Proceedings of Enviroinfo and ICT for Sustainability 2015 (ACSR-Advances in Computer Science Research), Copenhagen, Denmark, 22, pp. 97-107.

Reznik, T., Horakova, B., Szturc, R., 2015. Advanced methods of cell phone localization for crisis and emergency management applications. International Journal of Digital Earth, 8 (4), pp. 259-272

Schutt, P. et al., 2007. "OpenGIS ${ }^{\circledR}$ Web Processing Service", Wayland United States of America http://portal.opengeospatial.org/files/?artifact_id=24151 (8 Jun 2007).

Skokanova, H., 2013. Can we combine structural functionality and landscape services assessments in order to estimate the impact of landscape structure on landscape services?. Moravian geographical reports, 21 (4), pp. 2-14.

Stampach, R., Kubicek, P., Herman, L., 2015. Dynamic Visualization of Sensor Measurements: Context Based Approach. Quaestiones Geographicae, 34 (3), pp. 117-128.

United States Environmental Protection Agency, 1972. "Summary of the Clean Water Act 33 U.S.C. $\$ 1251$ et seq.", United States of America http://www2.epa.gov/lawsregulations/summary-clean-water-act (8 Oct 2015).

Warren, J., 2015. "Near-Infrared Camera", Boston, United States of America https://publiclab.org/wiki/near-infraredcamera (Jun 2015). 